\title{
QUANDO AS PALAVRAS SALTAM À VIDA, GERAM SENTIDOS E CRIAM CONSCIÊNCIA, FORMA-SE UM LEITOR: \\ LER ALÉM DOS SIGNOS - EXPERIENCIAR A ARTE CONSTITUÍDA DE PALAVRAS
}

\author{
WHEN WORDS JUMP OUT OF LIFE, GENERATE SENSES AND CREATE \\ CONSCIOUSNESS, THEN A READER IS BORN: \\ READING BEHIND THE LINGUISTIC SIGNS - EXPERIMENTING THE ART \\ BUILT UP BY WORDS
}

\author{
Gilmei Francisco Fleck ${ }^{1}$
}

\begin{abstract}
Resumo: Neste texto buscamos refletir sobre a formação do leitor no espaço escola e de como a leitura pode ser meio de descolonização em sociedade estratificadas. Conscientes de que o processo de humanização ocorre pelo acesso e pelo desenvolvimento da linguagem, compartilhamos considerações sobre a importância da leitura ao longo da formação integral. Apontamos para a necessidade da escola como instituição social de promover nessa trajetória a formação do leitor literário capaz de compreender que a linguagem é material maleável, manipulável à formação de discurso. O texto literário, neste sentido, é o mais precioso médio de confrontar o aluno com esse uso da linguagem. Esse processo de formação do leitor literário em busca da humanização do sujeito deve começar já nas séries iniciais do Ensino Fundamental. Nossas proposições estão fundamentadas nos pressupostos de Lajolo (1993), Candido (2004), Soares (2004), Colomer (2007), Petit (2008) Martins (2012), entre outros. Para que esse processo seja eficiente a escola não só deve atentar aos textos lidos, mas também à forma como a leitura está sendo mediada e incentivada pelos professores e realizada pelos alunos.
\end{abstract}

Palavras-chave: formação do leitor literário; processo de leitura; ensino de literatura

\begin{abstract}
In this text we discuss about the reader's formation inside de school and how reading is a way of decolonization in stratified societies. We are conscious that the process of humanization occurs through the access and development of language, so we share some considerations about the importance of reading along the integral process of a person's development. We appoint to the need to promote inside the school system itself the formation of literary readers along this trajectory, a reader who is able to understand that language is a manipulating material used to produce discourses. The literary texts in this sense are the most precious way to confront students with this specific used of language. This process of a literary reader's formation should start already along the first years of Primary School. Our proposals are based on theories established by author such as Lajolo (1993), Candido (2004), Soares (2004), Colomer (2007), Petit (2008) Martins (2012), besides others. To makes this

\footnotetext{
${ }^{1}$ Pós-doutor em Literatura Comparada e Tradução pela UVigo-VigolEspanha; Doutor em letras pelas UNESPAssis-SP\Brasil; Professor associado da Unioeste-Cascavel-PR\Brasil: Professor de Literatura Hispanoamericana e Cultura Hispânica na Graduação em Letras PortuguêsไEspanhol, de Literatura Comparada e Tradução no Programa de Pós-graduação em Letras-PPGL, professor de Literatura Infantil e Juvenil no Mestrado Profissional em Letras-Profletras-Unioeste-Cascavel-PRIUFRN-RN. Líder do Grupo de Pesquisa "Ressignificações do passado na América; processos de leitura, escrita e tradução de géneros híbridos de história e ficção - vias para a descolonização". E-mail: chicofleck@yahoo.com.br
} 
process being efficient the school needs not just to look at the texts which have been read, but also to the way readings is being mediated and incentivized by the teachers and how it is processed by the students.

Keywords: Reader's formation; Process of reading. Teaching of Literature. Introdução

Uma das mais esperadas experiências na vida é a entrada da criança na escola. Considera-se esse momento como um acontecimento que pode definir a relação do sujeito com a sociedade e o mundo. Pais e filhos vivem nesta fase uma mescla de sentimentos que vão do medo - que um possível fracasso possa acontecer - até a extrema alegria - causada pela superação das primeiras e vitais barreiras que esse universo impõe: adaptar-se à aprendizagem de duas novas habilidades: a leitura e a escrita.

Esse é o grande desafio da entrada do sujeito no sistema escolar: alfabetizar-se e letrarse. Qual é, afinal, a diferença entre esses dois processos que lidam diretamente com o universo representacional dos signos linguísticos? Tfouni (2004, p. 09) comenta que o primeiro "refere-se à aquisição da escrita enquanto aprendizagem de habilidades para a leitura, escrita e as chamadas práticas de linguagem" e o segundo "focaliza os aspectos sócio históricos da aquisição da escrita."

Segundo Magda Soares (2004), existe um fato curioso em relação ao termo letramento e as discussões sobre ele: surgiu em vários países ao mesmo tempo, porém com resultados distintos. Nos países ditos desenvolvidos, a discussão sobre "as práticas sociais de leitura e de escrita assumem a natureza de problemática relevante" (SOARES, 2004, p. 6), principalmente ao se constatar que uma parcela da população sabia ler e escrever, mas não era letrada e que os estudos sobre o letramento deveriam ser aprofundados para dar conta desta situação. Esse estudo específico sobre letramento deveria ser dissociado dos problemas concernentes à alfabetização.

Já no Brasil, segundo Soares, este conceito de letramento ainda está estreitamente ligado à alfabetização, principalmente nos “censos demográficos, a mídia, a produção acadêmica" (SOARES, 2004, p. 7), sendo que neste último, existem avanços e retrocessos. A autora cita como problema nesse contesto o fato de que há "perda da especificidade da alfabetização", o que estaria causando o "atual fracasso na aprendizagem." (SOARES, 2004, p. 9). Magda Soares usa o termo "invenção do letramento" para se referir ao fato de separar os termos alfabetização e letramento, e aponta que este último decorre da "necessidade de reconhecer e nomear práticas sociais de leitura e de escrita mais avançadas e complexas que 
as práticas do ler e do escrever resultantes da aprendizagem do sistema de escrita." (SOARES, 2004, p. 6). Então a alfabetização, apesar de ser um processo de suma importância, é somente a porta de entrada para o mundo letrado, onde as práticas sociais do uso da escrita é que vão determinar se uma pessoa está preparada ou não para o mundo da escrita. Soares (2004, p. 14), no entanto afirma:

Dissociar alfabetização de letramento é um equívoco porque, no quadro das atuais concepções psicológicas, linguísticas e psicolinguísticas de leitura e escrita, a entrada da criança [e também do adulto] no mundo da escrita se dá simultaneamente por esses dois processos: pela aquisição do sistema convencional de escrita - a alfabetização, e pelo desenvolvimento de habilidades de uso desse sistema em atividades de leitura e escrita, nas práticas sociais que envolvem a língua escrita - o letramento. Não são processos independentes, mas interdependentes, e indissociáveis: a alfabetização se desenvolve no contexto de e por meio de práticas sociais de leitura e escrita, isto é, através de atividades de letramento, e este, por sua vez, só pode desenvolver-se no contexto da e por meio da aprendizagem das relações fonema/grafema, isto é, em dependência da alfabetização.

No Brasil, segundo discutem a maioria dos especialistas, a escola continua centrando sua prática na alfabetização, priorizando a decoficação dos signos linguístico de forma hábil e eficiente como ápice do processo. É a eficiência neste processo de codificação e decodificação que delimita o sucesso ou o fracasso da criança no sistema educacional. A respeito disso, Angela Kleiman (2005, p. 20) comenta:

Pode-se afirmar que a escola, a mais importante das agências de letramento, preocupa-se, não com o letramento, prática social, mas com apenas um tipo de letramento, a alfabetização, o processo de aquisição de códigos [...], processo geralmente concebido em termos de uma competência individual, necessária para o sucesso e a promoção na escola.

Para se formar leitores, então, não basta que os indivíduos saibam decodificar e codificar com eficiência, é preciso que eles façam uso da habilidade de leitura e escrita em seus diversos contextos de interação e atuação. É dessa preocupação com o uso da leitura e da escrita que surge o termo letramento, que passa a ser compreendido como a capacidade do indivíduo de usar essas ferramentas como um meio de tomar consciência da realidade para transformá-la. Para que o letramento, sob o ponto de vista da prática social, seja de fato desenvolvido, a escola não só deve atentar aos textos lidos, mas também à forma como a leitura está sendo mediada e incentivada pelos professores e realizada pelos alunos. Assim. é necessário levar em conta o que está sendo lido e a forma como esta leitura está sendo feita.

Dessa forma, não apenas a alfabetização deve ser discutida como um direito de todo cidadão, mas também o letramento, e dentro dele: o letramento literário, por se configurar em um saber estético elaborado; ou seja, todos, indistintamente, deveriam ter a possibilidade de 
apropriar-se da riqueza cultural, científica e artística produzida historicamente pela humanidade, incluindo-se a literatura, pois

[...] é à literatura, como linguagem e como instituição, que se confiam os diferentes imaginários, as diferentes sensibilidades, valores e comportamentos através dos quais uma sociedade expressa e discute, simbolicamente, seus impasses, seus desejos, suas utopias. Por isso a literatura é importante no currículo escolar: o cidadão, para exercer plenamente sua cidadania, precisa apossar-se da linguagem literária, alfabetizar-se nela, tornar-se seu usuário competente, mesmo que nunca vá escrever um livro. (LAJOLO, 1993, p. 106-107).

Nossa sociedade precisa, pois, entender não só a diferença entre alfabetização e letramento, mas, e antes de todo, compreender a importância que tem numa sociedade estratificada como a nossa, resultado de um período de séculos de colonização, que ler é importante, vital e imprescindível à democracia, à igualdade social e à construção de uma existência digna. Nesse sentido discutimos ao longo deste texto como o sujeito pode se humanizar pelo aprendizado da leitura e, em especial, pela sua formação como leitor literário.

\section{A humanização pela linguagem: construções subjetivas que promovem crescimento}

A espécie homo sapiens, ao nascer, dá início ao seu maior processo de diferenciação frente aos demais animais que lhe são, biologicamente, muito próximos. A esse processo, que faz dessa espécie a mais desenvolvida no reino animal, chama-se humanização.

Contudo, esse não é um curso natural e nem exclusivamente biológico na formação do homem. Ele é, de fato, essencialmente histórico e cultural e só se instaura pela mediação dos adultos, por meio do acesso que se oferece ao ser em formação àqueles instrumentos já disponíveis à espécie para esse fim. Vale lembrar que a "[...] mediação é a interposição que provoca transformações, encerra intencionalidade socialmente construída e promove desenvolvimento" (2012, p. 46).

Esses instrumentos são oriundos do processo cumulativo da caminhada histórico social que revela as conquistas dos humanos ao longo da existência. Quanto aos instrumentos utilizados nesse processo de mediação entre a criança e o adulto eles,

[...] podem ser considerados técnicos e psicológicos. Ambos são produtos historicamente elaborados pela humanidade e orientam as realizações próprias do ser humano, posto que possibilitam a transformação do meio natural e a própria conduta humana. Os instrumentos técnicos são os produtos materiais visíveis e fisicamente construídos pelos homens, tais como ferramentas e aparatos tecnológicos dos quais dispomos para relacionarmo-nos com o meio. Já os instrumentos psicológicos são as chamadas funções psicológicas, que podem ser divididas entre elementares e superiores, pois são distintas pela natureza das relações que se firmam entre ambas. Entre elas, o destaque é para a linguagem. (POLON; PADILHA, 2017, p. 84). 
A linguagem, nesse contexto formador e evolutivo, constitui-se no mais aprimorado instrumento mediador que contribuiu, ao longo dos anos, para que os seres humanos superassem a forma de representação material do objeto, possibilitando, assim, que a palavra reproduzisse, no nível mental, abstrato e representacional, o objeto real.

Assim, a falta de acervo léxico ou sua grande limitação, afeta e prejudica a capacidade de reflexão, de exteriorização, de expressão do ser humano. Esta limitação de linguagem se reflete em todas as áreas imagináveis da existência, reduzindo seu universo de atuação e compreensão à mesma proporção de seu conhecimento, levando-o, às vezes, à beira da irracionalidade. Desse modo é compreensível o fato de que um vocabulário escasso e inadequado, incapaz de veicular impressões e concepções, mina o próprio desenvolvimento mental, limitando a capacidade de observar, compreender e até mesmo de sentir.

O processo histórico do desenvolvimento humano, articulado ao desenvolvimento da linguagem e do trabalho, exigiu do homem uma organização de suas ações. Logo, esse processo não deriva das vias naturais do desenvolvimento. Essa organização está representada pela consciência. A consciência é

[...] um sistema de conhecimentos que vai formando-se no homem à medida que ele
vai apreendendo a realidade, pondo em relação as suas impressões diretas com os
significados socialmente elaborados e vinculados pela linguagem, expressando as
primeiras através da segunda. Por tais razões é que podemos afirmar que a
consciência é social por natureza, isto é, socialmente condicionada em seus
determinantes e conteúdos. (MARTINS, 2017, p. 67).

As relações sociais instituem a consciência e o seu processo de desenvolvimento está articulado com o modo de produção da vida material dos homens. Ela tem suas estruturas consolidadas por meio da relação do homem com o trabalho e se concretiza pela linguagem, fazendo o ser humano compreender os significados sociais e, assim, atribui-los à sua própria vida particular de acordo com suas necessidades, seus sentimentos e seus motivos. Esse processo diferencia o homem dos demais animais e constitui-se na racionalidade humanizada. Conforme explicita Candido (2004, p. 180):

Humanização é o processo que confirma no homem aqueles traços que reputamos essenciais, como o exercício da reflexão, o afinamento das emoções, a capacidade de penetrar nos problemas da vida, o senso de beleza, a percepção da complexidade do mundo e dos seres, o cultivo do humor.

A transformação do homem em gênero humano depende, pois, da formação da consciência articulada às bases da vida real e das condições materiais do sujeito. Assim, "a 
consciência é a expressão ideal do psiquismo, desenvolvendo-se graças à complexificação evolutiva do sistema nervoso central pela decisiva influência do trabalho e da linguagem." (MARTINS, 2012, p. 28). Por isso, a consciência é traduzida na linguagem da vida real, pois emerge do mundo que contracena com a realidade. Formar leitores literários na escola coincide com a formação de um cidadão consciente

É preciso construir caminhos de interesse e familiarização com a arte literária na escola, valendo-se, para isso, a princípio dos mais simples e, depois, aos mais complexos, num processo de amadurecimento, oferecendo aos educandos o texto literário a princípio para uma familiarização e identificação e, aos poucos, acrescentar obras mais elaboradas e que demandam operações linguísticas e relações intertextuais mais complexas. Essa prática requer a mediação: uma sistemática, um planejamento, uma continuidade que conduza à satisfação e à realização pessoal, em primeira instância e, mais adiante, ao árduo trabalho da leitura crítica, do enfrentamento entre o lido e a realidade circundante em um grau mais consciente e profundo.

Desse modo podemos entender que a existência humana depende do processo de mediação dos signos e do desenvolvimento da consciência, a qual se constrói por intermédio do trabalho e da linguagem. Todo esse complexo sistema de aprimoramento do pensamento, da instauração da consciência e da intelectualização da criança é dependente da linguagem. Com esse desafio ela se enfrenta, uma vez mais, quando chega à escola e precisa aprimorar o seu conhecimento linguístico - já instituído pelos processos da audição e da fala - habilidades que ela domina antes de chegar ao espaço escolar, mas que, também, precisam ser ali aperfeiçoados.

Assim, o conhecimento - mediado pela linguagem - passa a ser elemento principal na construção da vida consciente, humanizada. Entre o conhecimento historicamente acumulado, o homem produziu as artes. Estas são sínteses dos grandes avanços alcançados pela espécie que, passo a passo, foi apreendendo e aprimorando os meios de "representação" da realidade.

As distintas artes, nesse sistema evolutivo da espécie humana, valeram-se de materiais diferenciados para alcançar a representação almejada da realidade circundante e, por meio dela, a síntese das realizações humanas no tempo e no espaço. Assim, mais uma vez nos deparamos com o fato de que a linguagem (fala) se posiciona na centralidade das relações sociais, humanizadas, que se instauram graças aos significados atribuídos aos signos e negociados dialogicamente nas interações. 
O significado da palavra "signo" vem do latim "signum" que é o elemento que designa ou indica outro, objeto que representa outro, elemento sensível de expressão cultural organizativo do comportamento humano que encerra uma materialidade (sinal) e ocupa o lugar de outra coisa. Isto é, daquilo que representa. Há uma grande quantidade de signos que o ser humano utiliza para representar outro elemento, embora, na escola se valorize de forma excepcional a escrita - a representação pelos signos linguísticos.

Ao operar ao nível da consciência dos indivíduos, todo signo demanda decodificação. É somente por meio da internalização dos signos, construídos historicamente e mediados pelo outro, que se institui o sujeito como ser humano. Daí a importância da instrução formal para que a criança, ou mesmo o adulto, alcance o conhecimento que lhe possibilite decodificar e codificar a linguagem por meios dos signos. Destaca-se, assim, a absoluta relevância do ensino da leitura na instrução formal que deve ser garantida ao sujeito para que possa se humanizar.

À escola cabe, por excelência, o papel de formar leitores. A sociedade pode, e deve, participar desta tarefa; contudo, é no espaço institucional da escola como um todo que o processo de leitura precisa ser instaurado e conduzido de forma a tornar-se um ato de reflexão. Todos os segmentos da instituição precisam comprometer-se com tal tarefa, pois essa fica fadada ao fracasso quando relegada a uma ou outra disciplina específica ou a um ou outro profissional da educação. Nesse sentido cabe lembrar-nos de que

[...] a leitura é um dos meios mais eficazes de desenvolvimento sistemático da linguagem e da personalidade. Ela favorece a remoção de barreiras educacionais, concedendo oportunidades mais justas de educação, principalmente através da promoção do desenvolvimento intelectual e aumenta a possibilidade de normalização da situação pessoal de cada indivíduo. (BAMBERGER, 1991, p. 10).

Saber ler não significa somente saber decifrar ou decodificar os signos linguísticos. Obter o pleno conhecimento e domínio da arte de ler constitui-se em uma caminhada, um processo, no qual cada novo passo aprendido abre inúmeras possibilidades de reflexão e indica novos rumos a prosseguir na busca de soluções. Deste modo, a leitura estimula a capacidade de abstração, instrumentalizando o indivíduo a lidar, de forma consciente, com outros códigos e linguagens com os quais terá, necessariamente, que enfrentar-se ao longo de sua caminhada educacional.

No processo de representação da realidade pelas artes, já antes mencionado, devemos, no contexto da instrução formal escolar e da necessidade de, nele, priorizar o aprendizado da 
leitura, destacar a arte literária. Ela é a arte que explora ao máximo a potencialidade do imenso poder representativo e metafórico dos signos linguísticos, para revelar a multiplicidade de significados que um signo pode adquirir quando disposto a um processo de manipulação consciente deste material que é a linguagem. Exercitar isso no contexto escolar é descolonizar porque "[...] reaprender a linguagem do prazer, reconhecê-la e desenvolvê-la na leitura é uma forma de resistência a uma concepção utilitária (e burguesa) de leitura" (LAJOLO, 1993, p. 27).

Assim, a leitura do texto literário torna o mundo e suas relações mais compreensíveis, principalmente para as crianças, por não possuírem ainda uma vivência mais aprofundada e uma bagagem significativa das diversas esferas da vida humana. Dessa maneira, a criança, pelas características de sensibilidade que são próprias a essa fase do desenvolvimento, identifica-se com a representação da arte literária, à medida que

\footnotetext{
[...] é à literatura, como linguagem e como instituição, que se confiam os diferentes imaginários, as diferentes sensibilidades, valores e comportamentos através dos quais uma sociedade expressa e discute, simbolicamente, seus impasses, seus desejos, suas utopias. Por isso a literatura é importante no currículo escolar: o cidadão, para exercer plenamente sua cidadania, precisa apossar-se da linguagem literária, alfabetizar-se nela, tornar-se seu usuário competente, mesmo que nunca vá escrever um livro. (LAJOLO, 1993, p. 106-107).
}

O ser humano sempre buscou, de forma relevante, desenvolver a sua capacidade comunicativa, valendo-se, para tanto, das formas de linguagem que lhe eram conhecidas, empregando-as num processo contínuo de aperfeiçoamento, a fim de alcançar a compreensão do mundo que o cerca pelo entendimento dos fatos do passado que o geraram. Isso lhe é possível uma vez que, ao longo deste processo evolutivo da comunicação humana, também se chegou ao conhecimento necessário para registrar o que se fala, se pensa, se inventa e se descobre, pelo emprego de meios que garantam o acesso a essas informações no futuro.

Esses registros permitem um constante fluir de informações ao longo do tempo. Como resultado desse processo cumulativo de experiências, surge na consciência do sujeito em formação um senso de passado e futuro, não somente de presente. Essa tríplice visão é a que permite a interpretação da realidade em suas múltiplas dimensões e impulsiona o sujeito a transformar em seu meio aquilo que não lhe é conveniente ou que lhe causa desgosto.

Tal interpretação dá-se por meio de um processo crítico de leitura do mundo que, juntamente com a capacidade inerente ao homem de transformar o meio socioeconômico, político e cultural no qual está inserido, possibilita-lhe uma adaptação à realidade. Baseada no 
conhecimento e compreensão do passado, que leva à análise, ao entendimento e à confrontação do presente, essa adaptação, por sua vez, induz o indivíduo a posicionar-se e, consequentemente, a buscar mudanças. Tais mudanças implicarão em transformações em seu futuro, o que gera um constante processo de busca de identidade própria e coletiva.

Considerando que a leitura da palavra, conforme Freire (1982), é precedida pela leitura do mundo, o trabalho com a leitura, na escola, precisa pautar-se nas relações sociais contidas nas obras, as quais despertam as conexões com as experiências dos leitores. Assim, o ensino da leitura não deve voltar-se, apenas, à compreensão da funcionalidade da escrita em gêneros estáticos, reproduzíveis e de uso comum e corrente. A linguagem precisa ser ensinada na escola como "matéria maleável", como meio de produzir discursos que, em todos os sentidos, revelam a manipulação dos signos linguísticos de acordo às intenções e às ideologias de quem os produz.

Ao encontrar na arte literária as representações sócio históricas de gerações e gerações - sejam do passado, do presente ou mesmo projeções delas ao futuro - o sujeito dispõe de uma via crítica de inter-relações que transcende o tempo e o espaço aos quais estamos aprisionados na realidade, pois

[...] la literatura nos permite vivir en un mundo cuyas leyes transgreden las leyes inflexibles por las que transcurre nuestra vida real, emancipados de la cárcel del espacio y del tiempo, en la impunidad para el exceso y dueños de una soberanía que no conoce límites. (VARGAS LLOSA, 2002, p. 394).

Neste processo imaginativo, fantasioso, representacional, o leitor transforma o texto e é transformado por ele, pois, nesta modalidade de leitura, é-lhe possível alterar sentidos, distorcer, reempregar, manipular as palavras e introduzir variantes, ao mesmo tempo em que “[...] também é transformado: encontra algo que não esperava e não sabe nunca aonde isso poderá levá-lo.” (PETIT, 2008, p. 28-29). Assim, a arte literária, como objeto de leitura, prioriza a abertura da consciência à liberdade, à expressividade, às emoções e aos sentimentos. Nesse sentido, cabe ressaltar que "a literatura nos prepara para ler melhor todos os discursos sociais" (COLOMER, 2007, p. 36), mesmo que a escola priorize apenas uma pequena gama deles. Isso acarreta no empobrecimento da formação do sujeito e numa humanização deficiente e precária que se revela em ações do sujeito na sociedade.

O texto literário, portanto, estimula a formação de mentes livres e emancipadas. Assim,

[...] compreender a importância da iniciação do sujeito no mundo literário, por meio da exploração da literatura infantil e infantojuvenil, é lançar boas sementes num solo 
fértil, que, no futuro, revelará frutos como a criticidade, o engajamento social e político, a consciência de que todo ser humano é agente histórico - elementos constituintes das ações de um leitor crítico, transformador do meio pela capacidade de compreensão e pelo domínio do poder da palavra como construtora de discursos. (FLECK, 2017, p. 30).

A leitura do texto literário oferece essa fantástica possibilidade de romper barreiras, sejam elas geográficas, históricas, cronológicas, culturais ou mesmo psicológicas. Limites que, às vezes, parecem intransponíveis na formação do sujeito são removidos pela instrução, o conhecimento e a tomada de consciência decorrentes do processo de leitura. A trajetória da formação do leitor literário - que compreende os níveis de leitura sensorial, emocional, compreensivo, interpretativo, conscientizador, analítico e, finalmente, crítico - gera efeitos que podem transcender ao texto e converter-se em ação e transformação na vida do leitor. Ler é pôr-se a caminho da ação, do não conformismo com a realidade, da produção do saber e da realização pessoal. Ela é a base lógica sobre a qual todo e qualquer processo de abstração pode ser construído.

A história de nosso país, inalteradamente, segue revelando que "ler continua sendo coisa das elites, no início de um novo milênio" (ROJO, 2004, p. 1). Como poder concentrado nas camadas elitizadas, o conhecimento do ato de ler e, em consequência o de escrever, estabelece os limites que interpolam a estratificação social.

$\mathrm{O}$ acesso ao conhecimento diferenciado, aquele que permite ao leitor reconhecer sua identidade, seu lugar social, as tensões que animam o contexto em que vive ou sobrevive, e, sobretudo, a compreensão, assimilação e questionamento seja da própria escrita, seja do real em que a própria escrita se inscreve (Osakabe, 1982), o domínio da leitura assim entendida é ameaça à dominação, por isso negado às camadas populares. (SOARES, 2009, p. 25).

Zilberman (2004) chama atenção para a leitura literária como modalidade de educação e esclarece que, na trajetória do ensino da Literatura, por muitos séculos, o conhecimento dos clássicos e do cânone consagrado foram privilegiados, mas, nas últimas décadas, “[...] primeiro jogou-se ao mar a carga da história; depois, foi abandonada a própria literatura, desfeita na definição imprecisa de texto.” (ZILBERMAN, 2004, p. 18). Ela explica que

[...] essas opções decorreram de um processo, ele mesmo, histórico, relacionado à ascensão à escola pelas classes populares, que, assim, permanecem alienadas da tradição e do passado, ao qual podem não pertencer, com o qual podem não se identificar, mas que se relaciona à formação da identidade nacional, com a qual devem interagir, seja para aceitá-la, seja para contrariá-la. (ZILBERMAN, 2004, p. $18)$. 
Uma rápida pesquisa na história da educação no Brasil revela que, enquanto o acesso ao sistema de Ensino Fundamental e Médio era bastante elitizado havia disciplinas específicas de literatura em vários anos escolares. À medida que as classes populares começaram a ter acesso mais frequente à escola podem se ver várias alterações no sistema curricular e entre elas se destaca a retirada gradativa das disciplinas de literatura. Isso, como ação de manutenção do colonialismo, não é difícil de entender, pois a camada elitizada, que exerce o poder, sempre esteve consciente de que

[...] a literatura tem sido um instrumento poderoso de instrução e educação, entrando nos currículos, sendo proposta a cada um como equipamento intelectual e afetivo. Os valores que a sociedade preconiza, ou os que consideram prejudiciais, estão presentes nas diversas manifestações da ficção, da poesia e da ação dramática. A literatura confirma e nega, propõe e denuncia, apóia e combate, fornecendo a possibilidade de vivermos dialeticamente os problemas. (CANDIDO, 2011, p. 177178).

Ao analisar a construção histórica da formação do leitor em nossa realidade, Regina Zilberman (2009) observa que

[...] até um certo período da história do Ocidente, ele [o leitor] era formado para a literatura; hoje, é alfabetizado e preparado para entender textos, ainda orais ou já na forma escrita, como querem os PCNs, em que se educa para ler, não para literatura. Assim, dificilmente a literatura se apresenta no horizonte do estudante, porque, de um lado, continua ainda sacralizada pelas instituições que a difundem; de outro, dilui-se no difuso conceito de texto ou discurso. (ZILBERMAN, 2009, p. 17).

Assim, é claro que, à medida que as classes populares foram acedendo à escolarização, um projeto muito mais amplo, lenta, mas progressivamente, começou a excluir a literatura dos currículos e essa atitude colonizadora encontrou no seio da própria instituição escolar uma legião de defensores. Ela, gradativamente, estendeu-se também às propostas de formação de docentes, com ênfases, cada vez mais marcantes, nos aspectos estruturais da língua, deixando a manipulação da linguagem pela arte literária relegada a planos menos impactantes, desviando-se do fato de que "a riqueza polissêmica da literatura é um campo de plena liberdade para o leitor, o que não ocorre em outros textos.” (AGUIAR; BORDINI, 1988, p. 15).

Para Freire (2003, p. 18), o ato de ler está envolvido em um processo "que não se esgota na decodificação pura da palavra escrita ou da linguagem escrita, mas que se antecipa e se alonga na inteligência do mundo.” A formação de um leitor pleno, proficiente, tem como resultado um cidadão pensante, capaz de assimilar aquilo que lê, que tem a leitura como uma ferramenta capaz de facilitar sua vida e ajudá-lo a compreender e experienciar o mundo. Já a 
escrita passa a ser, para este leitor, um meio de expressão privilegiado que pode lhe garantir seus direitos.

Sob os ditames de preceitos colonizadores que ainda vigoram na atualidade, a escola começou, assim, a produzir usuários de textos (muitos deles não proficientes e nada eficientes) ao invés de gerar leitores literários capazes de entender que a linguagem, assim como o gesso, as tintas, o mármore e tantas outras matérias primas que geram obras de artes, é absolutamente manipulável. Efeito disso é o imenso contingente de sujeitos altamente manipuláveis, alienáveis pela linguagem, que hoje defendem o fim de uma educação pública, gratuita e de qualidade. Sem dúvidas são estes os usuários de textos, saídos da escola, mas que rechaçam a arte literária já que

[...] a obra literária acaba por fornecer ao leitor um universo muito mais carregado de informações, porque o leva a participar ativamente da construção dessas, com isso forçando-o a reexaminar a sua própria visão da realidade concreta. (AGUIAR; BORDINI, 1988, p. 15).

Nesse curso histórico, em breve, creio, não serei o único sonhador a sentir saudades da época em que a literatura era "modelo" de linguagem para a educação de qualidade. Essa será uma nova era, na qual entenderemos, finalmente, que

[...] a literatura corresponde a uma necessidade universal que deve ser satisfeita sob pena de mutilar a personalidade, porque, pelo fato de dar forma aos sentimentos e à visão do mundo, ela nos organiza, nos liberta do caos e, portanto, nos humaniza. Negar a fruição da literatura é mutilar a nossa humanidade. (CANDIDO, 1995, p. 06).

A formação de professores sensíveis à leitura da literatura na sala de aula não tem sido prioridade nos cursos de graduação. Para comprovar isso basta ver o espaço que o ensino de literatura ocupa nos currículos. Na pós-graduação não é muito diferente, pois a grande maioria dos estudos literários realizados no nível de mestrado e doutorado passa longe das questões do ensino. Quando se aprovou instituir no Mestrado Profissional em Letras - Profletras, ao lado de linhas de ação voltadas à funcionalidade da linguagem, também a linha de "Estudos literários”, deu-se um passo firme em direção à formação de docentes do Ensino Fundamental mais conscientes e melhor preparados a lidar com o texto literário em sala de aula.

A leitura de fruição pode ser um caminho para transformar a atual escola num espaço mais adequado à aprendizagem significativa, porque esta é a leitura que, segundo Geraldi (2006), “está ligada ao prazer, ler por ler, sem interesse pelo controle de resultado, ler gratuitamente". Algo que vemos possível e significativo quando é realizado com um trabalho voltado ao texto literário, pela leitura subjetiva que tais textos promovem. $\mathrm{O}$ encanto pela 
leitura deve começar na infância, incentivado pela família, estimulado e, estrategicamente, induzido na escola.

A experiência da vida escolar é decisiva para a experiência de leitura e, consequentemente, para a de mundo. Sabemos que esta experiência em nossos dias encontrase em crise, debilitada e desestruturada, pois não produz os frutos que dela se espera. Com o passar dos anos, por meio de um projeto de manutenção da colonização, instituíram-se muitos mecanismos que não permitiram o surgimento de uma grande massa de cidadãos capazes de efetuar uma leitura crítica, conscientizadora e transformadora da realidade e a escola foi um dos canais usados para atingir esses objetivos. Prova disso é a posição de uma grande massa de profissionais da educação em relação à leitura literária em sala de aula. Contudo, essa massa se enfrenta, por outro lado com um conjunto humanizado de profissionais que se esforça pela utopia de uma sociedade leitora.

\section{Considerações finais}

Conforme afirma Cagliari (2005, p. 160), “[...] de tudo o que a escola pode oferecer de bom aos alunos é a leitura, sem dúvida, o melhor, a grande herança da educação. É o prolongamento da escola da vida, já que a maioria das pessoas, no seu dia a dia, lê muito mais do escreve." A escola deve buscar meios para solidificar a prática de leituras no seu interior, propiciar o desenvolvimento do sujeito e conduzir o aluno à apropriação da riqueza contida em uma obra literária, contribuindo para a formação do gosto do leitor pela arte literária, pois "a leitura seria a ponte para o processo educacional eficiente, proporcionando a formação integral do indivíduo.” (MARTINS, 2012, p. 25).

A leitura é um ato social essencial para a formação humana, aprende-se a ler para ler criticamente o mundo, para buscar os sentidos no texto que são determinados pela bagagem sociocultural que o leitor traz consigo desde os primeiros momentos de sua humanização. Portanto, a literatura nos propicia caminhar por distintas veredas, presenteia-nos com aprendizagens significativas, com experiências que contribuem com a compreensão do mundo que nos rodeia por meio da fantasia e do imaginário. Diante dessa experiência, o leitor, fundamentado na sua leitura de mundo, pode dialogar com o texto, levantar outras questões, e ir se desenvolvendo culturalmente. 
Uma vez instaurada a fase inicial da alfabetização e o aluno comece a dar passos seguros no processo fundamental de decodificação dos signos linguísticos, há que considerarse uma nova fase: a da leitura literária como meio de expansão de seu imaginário, de sua criatividade e da compreensão do uso metafórico dos signos linguísticos. Nada pode ser mais efetivo para que alguém se liberte do que aprender a usar, ou valer-se, dos mesmos instrumentos que o dominaram. No nosso caso: valer-se da leitura e da escrita para nos descolonizarmos.

A escolarização é um sistema hierárquico que sempre considerou uma elevação de níveis. Assim, das séries iniciais - supostamente dedicadas mais à alfabetização básica - até o $5^{\circ}$ ano escolar, o pequeno aprendiz passa por uma série de enfrentamentos com o universo da construção do saber no qual o domínio das habilidades de leitura e de escrita são consideradas fundamentais. Das primeiras decifrações, decodificações e inferências que marcam profundamente a experiência da vida escolar, espera-se que haja, gradativamente, uma ampliação no domínio do código escrito e, consequentemente, um incremento na quantidade, extensão e complexidade do material de leitura. O processo de leitura, nesse sentido, também necessita ser nivelado, a fim de contemplar a sucessiva progressão na caminhada formativa do sujeito.

Nesse sentido, a utilização do texto literário na alfabetização, por meio das práticas de ler e ouvir histórias, pode, sim, contribuir no processo de transição da fala para a escrita, ou seja, na aquisição e manejo do código escrito (ampliação vocabular, incorporação de estruturas linguísticas, etc). Cabe aqui ressaltar que essa prática com o texto literário deve ser de natureza quantitativa e qualitativa: é necessário que o professor propicie ao aluno o acesso a vários tipos de textos e obras, sem perder de vista a qualidade (estética e linguística) de cada uma delas. Assim, aprender a ler e a escrever, apesar de ser uma tarefa complexa, pode se tornar mais fácil se, desde o início, a criança encontrar um ambiente rico e motivador, que estimule novas descobertas e que oportunize, gradativamente, o contato com as complexidades da língua.

Nesse contexto, a literatura infantil e infantojuvenil vêm solidificar o espaço da leitura na escola enquanto formação de leitores literários, tendo em vista que ela pode proporcionar a possibilidade de a criança adentrar num mundo diferente: num mundo de sonhos e ações das personagens das histórias, que desmistificam preconceitos e permitem-lhe relacionar fatos com sua própria vida, numa forma de tornar o mundo mais compreensível e mais humano. 
Desse modo, se investirmos um pouco mais de tempo na formação do leitor literário na escola, antes de confrontarmos as crianças com o processo de produção escrita, podemos, seguramente, contar, também, com escritores mais proficientes ao longo da caminhada. Não cercear o mundo imaginativo e fabulativo das crianças quando elas entram na escola com limitações impostas pela linguagem denotativa - a qual também devem aprender a conhecer e utilizar ao longo do processo - é apostar no sucesso da caminhada à formação leitora.

\section{Referências}

BAMBERGER, R. Como incentivar o hábito da leitura. 5ed. São Paulo: Cortez, 1991.

BORDINI, M. da G.; AGUIAR, V. T. de. A formação do leitor: alternativas metodológicas. Porto Alegre: Mercado Alegre, 1988.

CANDIDO, A. Vários escritos. São Paulo: Duas Cidades, 1995.

CANDIDO, A. Inquietudes na poesia de Drummond. In: Vários escritos. 4. ed. (reorganizada pelo autor), São Paulo: Duas Cidades; Rio de Janeiro: Ouro sobre Azul, 2004.

CANDIDO, A. O direito à literatura. In: Vários escritos. Rio de Janeiro: Ouro sobre Azul, 2011.

COLOMER, T. Andar entre livros: a leitura literária na escola. São Paulo: Global, 2007.

FLECK, G. F. Formação do Leitor: um projeto socioeducacional - uma trajetória para a vida cidadã. In: FLECK, G. F. (Org.). Literatura Infantojuvenil: desafios para o letramento literário - pesquisas e experiências no âmbito escolar. Curitiba: CRV, 2017.

FREIRE, P. Educação como prática de liberdade. Rio de Janeiro: Paz e Terra, 1982.

FREIRE, P. Pedagogia do Oprimido. 36.ed. Rio de Janeiro: Ed. Paz e terra, 2003.

KLEIMAN, A. Preciso ensinar o letramento? Não basta ensinar a ler e escrever? Ministério da Educação. Campinas: CEFIEL/UNICAMP, 2005.

LAJOLO, M. No mundo da leitura para a leitura do mundo. São Paulo, SP: Ática, 1993.

MARTINS, M. H. O que é leitura. São Paulo: Brasiliense, 2012.

PETIT, M. Os jovens e a leitura: uma nova perspectiva. Tradução de Celina Olga de Souza. São Paulo: Editora 34, 2008.

POLON, G. X. P; PADILHA, A. M. L. Apontamentos sobre o desenvolvimento do psiquismo humano: desafios e possibilidades para a educação escolar. Educação em Foco, Piracicaba, ano 20, n.32, p.79-99, set/dez. 2017. Disponível em: Acesso: 20 mar. 2019. 
ROJO, R. Letramento e capacidades de leitura para a cidadania. São Paulo: SEE: CENP, 2004. Texto apresentado em Congresso realizado em maio de 2004.

SOARES, M. Alfabetização e Letramento, Caminhos e Descaminhos. Revista Pátio. ano VIII, n. 29 , p. 20, fev/abr. 2004.

SOARES, M. Letramento: um tema em três gêneros. 3 ed. Belo Horizonte: Editora Autêntica, 2009.

TFOUNI, L. V. Letramento e alfabetização. 6.ed. São Paulo: Cortez, 2004.

VARGAS LLOSA, M. La verdad de las mentiras. Buenos Aires, Aguilar, Altea, Taurus, Alfaguara, S/A, 2002.

ZILBERMAN, R. Estética da recepção e história da literatura. São Paulo: Ática, 2004.

ZILBERMAN, R. A escola e a leitura da literatura. In: ZILBERMAN, R.; RÖSING, T. M. K. Escola e leitura: velha crise, novas alternativas. São Paulo: Global, 2009.

Recebido em 20 de setembro de 2019. Aceito em 05 de novembro de 2019. 